\title{
ИСТОРИЯ ПЕДАГОГИКИ
}

Вестник ПСТГУ

Серия IV: Педагогика. Психология.

2017. Bun. 45. C. 11-30

\author{
Безрогов Виталий Григорвевич, \\ д- $\rho$ пед. наук, \\ 2л. науч. сотр. Института стратегии \\ развития образования $Р A O$

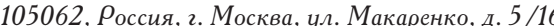 \\ bezrogov@mail.ru
}

\section{К ВОПРОСУ О РАННИХ ПЕРЕВОДАХ «ORBIS SENSUALIUM PICTUS» ЯНА АМОСА КОМЕНСКОГО НА РУССКИЙ ЯЗЫК}

\author{
В. Г. БЕЗРОГОВ
}

\begin{abstract}
Рассмотрено возникновение интереса к учебному пособию «Мир чувственных вещей в картинках» великого моравского педагога Яна Амоса Коменского в российской педагогической культуре. На материале изучения западноевропейских изданий с рукописными маргиналиями и отдельных рукописей, содержащих переводы этого учебника с немецкого и латыни на русский, показаны этапы предыстории появления первого полного издания Orbis sensualium pictus на русском языке. Первые зафиксированные источниками попытки его перевода на русский относятся к 1710-м гг., когда в Москве прекращают работать «немецкие школы» и возникает «дидактический вакуум» в преподавании иностранных языков. Второй этап относится к 1730-м гг., когда формируется потребность в многоязычном пособии и из немецко-латинского учебника пробуют самостоятельно сделать немецко-латино-франко-русский. Примерно полвека зреющего к Orbis pictus интереса находят свой результат в пятиязычном латино-руссконемецко-итальяно-французском издании 1768 г., выполненном на основе четырехъязычного нюрнбергского 1755 г. Изучение контактов нескольких педагогических культур по поводу подготавливаемых в их среде пособий является важной частью исследования истории начального образования в православном регионе.
\end{abstract}

Когда элемент или феномен одной педагогической культуры переходит в другую (с той или иной степенью трансформации и переопределения в процессе их диалога), такому переходу обычно предшествует период контакта, зарождения интереса к иному как возможному своему. Осуществляются предварительные, «апокрифические», попытки культурной рецепции феномена, не всегда с первого раза удачные, но в позитивном итоге прокладывающие фарватер для будущего прочного заимствования. Такой период представляет для историко-

* Работа поддержана грантом Фонда развития ПСТгУ «Начальная ступень православного образования: конструирование содержания, принципы разработки учебных пособий и методик преподавания» (05-0616/КИП 2) и грантами Отделения социальных и гуманитарных наук РФФИ 17-06-00075 и 17-06-00288. Сердечно благодарю О. Е. Кошелеву и Л. В. Мошкову за идею данной работы и постоянную поддержку в процессе ее осуществления. 
педагогической науки особый интерес, поскольку диалог практик и дискурсов лежит в основе эволюции педагогики как профессии и системы. Возможность подобной реконструкции, хотя бы частичной, всегда является актуальным вызовом, значимым для профессионального педагогического сознания.

В данной статье мы коснемся предыстории появления на русском языке знаменитого учебника Яна Амоса Коменского «Oribis sensualium pictus» (далее ОР). Составленный к 1653 г. и впервые полностью изданный в 1658 г. в Нюрнберге в двуязычном латино-немецком варианте, он должен был вести человека к овладению латынью как всеобщим языком ${ }^{1}$. Пособие, приобретшее сразу очень большую популярность, в XVII-XVIII вв. выходило не только в различных двуязычных изданиях, но и в трех-, четырех- , пяти- и даже шестиязычных вариантах. Его применяли для одновременного и перекрестного изучения латыни и новоевропейских языков. Когда ОР стал известным в Московии и вошел с помощью учителей московской Немецкой слободы в практику школьного и/или домашнего обучения, вскоре возникла идея его перевода на русский.

Первые следы подобных намерений связаны с именем Иоганна Эрнста Глюка (1652-1705). Известно, что для своей московской школы он предлагал издать переводы других учебников Коменского - Vestibulum и Janua². Вместе с тем в 1705 г. выходивший в Лейпциге немецкоязычный журнал «Die europäische Fama, welche den gegenwärtigen Zustand der vornehmsten Höfe entdecket» сообщал в панегирике-некрологе об осуществлении Глюком перевода in Russischer Sprache не только «Преддверия» и «Отверзтой двери к языкам», но также и «Мира в картинках» ${ }^{3}$. Однако ни экземпляров, ни других конкретных и бесспорных следов перевода указанных книг в московских и петербургских библиотеках и архивах (РГБ, НБ МГУ, РГБИЛ, РГАДА, ГПИБР, НБ РГГУ, НПБ им. К. Д. Ушинского, РНБ, БАН, СПбФ АРАН) нами пока не обнаружено 4 . Известно, что Глюк не-

${ }^{1}$ Безрогов В. Г., Куровская Ю. Г. Международный аспект образовательного пространства: Orbis pictus Коменского как проект учебника для всех стран // Информационное пространство и дети: образовательные возможности и манипулятивные воздействия. Сб. научн. тр. / К. В. Султанов, ред. СПб., 2016. С. 298-307; Они же. К истории названий учебных книг как способов организации образовательной информации: Orbis pictus Коменского // Символическая вселенная ребенка: между информацией и знанием. Сб. научн. тр. / К. В. Султанов, ред. СПб., 2016. С. 217-225.

${ }^{2}$ Рыжков А. Н. Образование в «немецких» школах Москвы в первой четверти XVIII века // Вопросы образования. 2007. № 2. С. 379; Пекарский П. П. Наука и литература въ Россіи при Петре Великомъ: изследованіе П. Пекарскаго. СПб., 1862. Т. 1. С. 128.

${ }^{3}$ Philipp Balthasar Sinold von Schütz (Hrsg.). Die europäische Fama, welche den gegenwärtigen Zustand der vornehmsten Höfe entdecket. Der 35. Theil. Leipzig, 1714 (repr. 1705, 1708). S. 789-790.

${ }^{4}$ Хранящийся в РГАДА перевод первых двадцати пяти страниц издания Vestibulum'a 1704 г., выполненный одним почерком и носящий следы правки еще тремя другими (БМСТ 1814a), не может быть отнесен к обсуждаемой группе рукописей, так как выполнен на бумаге 1720-1780-х гг. Благодарю за экспертизу бумаги ст. научн. сотр. РГАДА Л. В. Мошкову; науч. сотр. НИОР БАН Н. А. Бережную и зав. чит. залом СПбФ АРАН Е. Н. Груздеву за проведенную по моей просьбе проверку рукописей XVII-XVIII вв., хранящихся в данных учреждениях; сотрудников Нац. музея в Праге Яну Конечну и Якуба Хобжу за помощь в сканировании рукописи IX.Е.41 и выяснении ее истории; сотрудников РГАДА, МК РГБ, НИОРК НБ МГУ и других библиотек и архивов за неизменную благожелательность и помощь в изысканиях. Указание в подготовленной К. Пильцем библиографии всех изданий ОР рукописного пере- 
В. Г. Безрогов. К вопросу о ранних переводах «Orbis sensualium pictus» Яна Амоса Коменского...

редко выдавал желаемое/планируемое за действительное (в программе обучения были названы дисциплины, никогда в его школе не преподававшиеся: география, философия, этика, политика, иврит, сирийский, арамейский, греческий, арифметика, танцы, верховая езда). Можно предположить, что из-за отсутствия средств и занятости Глюка «Грамматикой российского языка» к переводу ОР он не приступал 5 . Возможно, перевод ОР обсуждался Глюком с коллегами по школе и корреспондентами, но документального подтверждения и этому пока не обнаружено. В. Н. Топоров пишет о вакууме вокруг Глюка, его невоспринятости русской культурой ${ }^{6}$ Может быть, проект переводов ОР не состоялся и по этой причине. Для подготовки небольшого числа переводчиков, обучавшихся у Глюка и его преемников, полагалось достаточным наличие оригинальных изданий ОР.

В начале XVIII в. переводческий проект Глюка не был единственным. В отличие от него, предполагавшего с помощью OP обучение другим языкам жителей России, в 1720-х гг. англичанин Томас Консетт замыслил издание славянской грамматики (переведенного на латынь М. Смотрицкого по версии 1648 г. плюс немецкий перевод латинской грамматики русского языка Г. В. Лудольфа) и ее применение вместе с англо-латино-русским вариантом ОР для обучения русскому языку иноземцев ${ }^{7}$. В этом случае ОР выступил бы проводником в русский синтаксис и русскую речь.

Проекты о переводе ОР на русский возникали не только внутри России. Учебник, по-видимому, привлек внимание кого-то из находившейся в Праге в 1716-1721 гг. группы переводчиков, правда посланных туда отнюдь не ради Коменского $^{8}$. О пражском проекте мы скажем чуть ниже, поскольку, скорее всего,

вода Глюка, якобы хранящегося в БАН, является ошибкой либо этот перевод был утрачен после 1912 или 1929 г., т. к. Пильц ссылается на чешские и словацкие библиографии Ч. Зирбта и Я. Гертвика (Pilz K. Die Ausgaben des Orbis Sensualium Pictus. Eine Bibliographie. Nürnberg, 1967. S. 154, 12). Возможно, за перевод ОР были приняты выполненные Глюком переводы текстов катехизисов, переписанный И. В. Паусом фрагмент «Grammatik der Russichen Sprache» Глюка, либо два анонимных перевода ОР, на титульном листе одного из которых есть отдельная запись «Паузе». См.: Карева Н. В. Становление традиции грамматического описания русского языка (1730-1750-е гг.) // Литературная культура России XVIII века. Вып. 4. СПб., 2011. С. 99-100; Чума A. А. Ян Амос Коменский и русская школа (до 70-х годов XVIII века). Братислава, 1970.

${ }^{5}$ Gluck J. E. Grammatik der russischen Sprache. 1704 / Hrsg. und mit einer Einleitung versehen von H. Keipert, B. Uspenskij und V. Zivov. Koln; Weimar; Wien, 1994; Johann Ernst Gluck 16531705: Pastor, Philologe, Volksaufklarer im Baltikum und in Russland (Fremdsprachen in Geschichte und Gegenwart) / Hrsg. H. Glück, I. Polanska. Wiesbaden, 2005; Mach Dich auf und Werde Licht Celies Nu, Topi Gaiss - Zu Leben und Werk von Ernst Gluck (1654-1705): Akten der Tagung Anlasslich Seines 300.Todestages vom 10. bis 13. Mai 2005 in Halle (Saale) / Hrsg. C. Shiller, M. Grudule. Wiesbaden, 2009; etc.

${ }^{6}$ Топоров В. Н. Эрнст Глюк, немецкий подвижник латышского и русского просвещения // Балто-славянские исследования. 1984. М., 1986. С. 261.

${ }^{7}$ Фундаминский М. И. К истории библиотеки Т. Консетта // XVIII век. Сборник 21: Памяти Павла Наумовича Беркова / Н. Д. Кочетков, отв. ред. СПб., 1999. С. 51; Грасгофф Х. Из истории связей Берлинского общества наук с Россией в 20-х годах XVIII в. // XVIII век. Сборник 7: Роль и значение литературы XVIII века в истории русской культуры. Л., 1966. С. 64-65.

${ }^{8}$ Мыльников А. С. Русские переводчики в Праге. 1716-1721 гг. // XVIII век. Сборник 9. Л., 1974. С. 279-296; Командорова Н. И. Русская Прага. М., 2009. Ср.: Чума А. А. Указ. соч.; 
результатом именно этого проекта стал хранящийся сейчас в Праге единственный полный перевод ОР на русский язык. Рукопись по неизвестной пока причине не была перевезена в Россию, как некоторые другие, и не была, соответственно, актуализирована. А. С. Мыльниковым установлено, что Максим Суворов, на тот момент «ученик [класса] пиитики» «московских славенолатинских школ», младший член группы переводчиков, возглавляемой префектом той же «школы» Феофилом Кроликом, вывез из Праги в Россию приобретенное им нюрнбергское издание ОР 1679 г. ${ }^{9}$ Максим Терентьевич, студент Карлова университета, в будущем справщик, миссионер, директор Московской синодальной типографии, переводчик с немецкого, знавший и латынь, - самый вероятный претендент на авторство оставшегося в Чехии перевода ОР.

Относительно конца XVII и XVIII вв. мы имеем еще один загадочный сюжет. В кратком каталоге погибшей в 1812 г. коллекции рукописей и печатных изданий проф. Ф. Г. Баузе (составлен коллекционером в 1807-1808 гг. для В. Н. Каразина, хлопотавшего о приобретении профессорской коллекции для Харьковского университета; издан в 1862 г.) под № 27 обозначено: «Комениев мир в лицах, напечатанный на пяти языках, 1679 г. На полях приписан к тому Российский перевод рукою того же времени, в четверку». Обнаруживший данную запись А. А. Чума отмечает, что выражение «того же времени» еще не гарантирует принадлежность перевода к XVII в. ${ }^{10}$ Однако само существование указанного экземпляра более чем сомнительно - по крайней мере, в описанном виде. Среди многочисленных переизданий и переиначиваний ОР, выявленных к настоящему времени, пятиязычное издание 1679 г. не значится. В 1679 г. в Нюрнберге было выпущено четырехъязычное латино-немецко-франко-итальянское издание $^{11}$. Возможно, «пять языков» подсчитаны Теодором Баузе с учетом записанного на полях книги перевода. Нам знакомо издание «Преддверия» Коменского 1704 г. с полным переводом текста и словаря, вписанным между строк. Если описанная Баузе-Каразиным книга имела вписанный полный перевод на русский, а не просто комментарии к напечатанному русскому переводу ОР, то он располагался бы не только на полях, но и внутри текстовых страниц, занимая все свободное место.

Пятиязычных изданий ОР, вышедших до 1812 г., насчитывается пять: 1685, 1750 (оба в Левочах, важном культурном центре тогдашней северной Венгрии), 1768, 1788 и, по-видимому, 1808 (в Москве и Петербурге). Если печатное пятиязычное издание существовало, то, вероятно, в списке была допущена ошибка расшифровки записи Баузе о годе издания - Каразиным либо впоследствии издателями. Из перечисленных вариантов для возможной ошибки ближе всего «1768». Пятиязычное издание 1768 г., включавшее перевод на русский, издано в четверть, а не в восьмую часть листа, как все западные издания ОР данного вре-

Скорвид С. С. Слово Я. А. Коменского в России: из истории перевода // Наследие Яна Амоса Коменского в контексте проблем современного образования. СПб., 2007. С. 113-122.

${ }^{9}$ РГИА ф.796, оп.5, д. № 445, л.3. Приведено по: Мыльников А. С. Указ. соч. С. 282.

${ }_{10}$ Чума А. А. Указ. соч. С. 16.

${ }^{11}$ Pilz K. Op. cit. S. 55, 128-131. Такое издание вывез М. Т. Суворов из Праги в 1720 г.: не оно ли было указано в первой версии каталога Баузе? Не пометки ли переводившего ОР Суворова или кого другого из его старших коллег оно несло на себе? Скорее всего, мы этого не узнаем. 
В. Г. Безрогов. К вопросу о ранних переводах «Orbis sensualium pictus» Яна Амоса Коменского...

мени. Если у Баузе в коллекции было одно из них, в этом случае на полях были, по-видимому, вписаны разъяснения к переводу. Однако московское пятиязычное издание 1768 г. совсем не имело картинок и потому не могло быть «в лицах». Неразрешимое противоречие.

Мы имеем множество вопросов без ответов. Кто/что подтверждает дату издания как 1679 г.? Поскольку книги утрачены в 1812 г., видел ли их de visu В. Н. Каразин в 1807-1808 гг.? Кто обработал список, переданный Каразину, покинувшему этот мир в 1842 г., для публикации в 1862? Кому принадлежит запись: «в лицах... в четверку»? Кто рассудил, что перевод сделан «рукою того же времени»? Баузе? Следующим после «Комения» в том же перечне идет «Собрание слов и речений Российского и Немецкого языков, расположенное по алфавиту, кажется, половины XVII в., в четвертку». Кому «кажется»? Профессиональному знатоку и коллекционеру Федору Григорьевичу Баузе, который приобрел это «собрание слов» и рассматривал, атрибутировал его? Почему же его запись об издании ОР столь неточна/противоречива? Не потому ли, что Баузе воспроизвел в первом списке предоставленную ему продавцом атрибуцию или желательную, о которой он мечтал? Только этим, вероятно, помимо кражи либо подлога, может быть объяснен тот факт, что запись об этой же (!) книге выглядит совсем иначе в более полной версии каталога, составленной после смерти Баузе для передачи всей коллекции в Общество истории и древностей российских.

В начале мая 1812 г. Ф. Г. Баузе завещал собрание Я. И. Росту. Тот создал полный и полагаемый точным перечень коллекции. Хотя он и сличал новый список со старым, но многие пункты добавил, а некоторые «немногие номера» нашел «иного содержания, нежели в первой описи показаны». Именно такой «номер» случился с пунктом 27, ставшим во втором списке пунктом 28 и утратившим всякий намек на Коменского и пятиязычие, но сохранившим сведения о переводе на русский: «Начало латинского языка, изъясненное по-немецки и по-французски с присовокуплением картин и письменного российского перевода». Более архаическое «в лицах» и указание на формат издания исчезло вместе с именем автора. Атрибутировал ли Коменскому данное издание тот, кто продал его Баузе, а коллекционер потом разобрался в подделке? Или Рост засомневался в атрибуции книги (в ней явно отсутствовал титул) и переделал запись? Сторонники раннего перевода ОР «тех же 1680-х годов» предпочитают о втором списке коллекции Баузе молчать. Но рассмотренная запись первой версии каталога Баузе остается загадкой, а не подтверждением переводов ОР на русский в конце XVII столетия. Можно только предполагать, что «начала латинского» с параллельными немецким и французским, имевшие иллюстрации, все же либо были каким-то изданием ОР - неизвестно точно какого года и места издания, либо аналогичным изданием другого автора. Рукописный перевод мог быть черновым или беловым вариантом, подготовленным к изданию 1768 г., или даже переводом времени максимальной популярности ОР в конце XVIII - начале XIX в., переписанным с печатного или вновь сделанным тем или иным учеником для самого себя ${ }^{12}$.

${ }^{12}$ Первую и вторую версии каталога коллекции см.: Каразин В. Н. Каталог славянороссийским рукописям (погибшим в 1812 году) профессора Баузе // Чтения Общества исто- 
Не вызывающие сомнения следы пробных переводов ОР на русский язык относятся к нюрнбергским изданиям 1682 и 1732 гг., по которым в 1710-е и 1730-е гг. в России его начинали переводить на русский, а с издания 1732 г. еще и на французский языки. В отличие от этих книг, заключающих переводы в самих себе (на вплетенных в них листах), рукопись полного перевода ОР, хранящаяся в библиотеке Национального музея в Праге (IX.Е.41), исполнена в отдельной тетради, привязать которую к конкретному изданию ОР не представляется возможным ${ }^{13}$.

\section{Издание 1682 года}

Библиотека Московской синодальной типографии (БМСТ в составе РГАДА) сохранила нюрнбергское издание 1682 г. Это самый ранний в БМСТ латинонемецкий экземпляр ОР, имеющий рукописный перевод ${ }^{14}$. Первый форзац содержит запись: «Книга Orbis sensualium pictus Германова». На 3-й странице обложки нанесена (свинцовым?) карандашом надпись «Василей Кипреяновъ» в графике XVIII в. Это может быть автограф одного из владельцев книги - Василия Васильевича, сына Василия Онуфриевича Кипреянова, библиотекаря Навигацкой школы, типографа и соратника Леонтия Магницкого в издании его «Арифметики». Василий Васильевич Киприянов, человек скорее торговый, не был чужд вопросам учености и образования, поскольку некоторое время после ухода отца в 1723 г. в иной мир продолжал его дело - частную гражданскую типографию ${ }^{15}$. Вероятно, запись относится либо ко времени до 1723 г., либо сразу после, так как впоследствии сын все меньше и меньше занимался книгами, перешел от издательских, книготорговых и библиотечных дел к производству кирпича ${ }^{16}$. На титульном листе слабо видный выцветший чернильный рисунок непонятного содержания - скорее всего, монограмма, но не Киприянова.

Издание было полностью расплетено, чтобы между печатными листами поместить чистые, а затем сшито заново в тетрадки и в переплет, который со-

рии и древностей российских при Московском университете. М., 1862. Кн. 2. Отд. 5; Моисеева Г. Н. «Собрание российских древностей» профессора Баузе // Труды Отдела древнерусской литературы. Т. 35. Л., 1980.

13 Эту рукопись, обнаруженную среди бумаг П. Й. Шафарика, обследовал сначала В. М. Истрин в 1894 г. Он определил ее «хрестоматией из 150 глав» XVIII-XIX вв. и без всяких объяснений отказался атрибутировать как перевод ОР, несмотря на совпадение структуры, титула и самого текста рукописи ОР (Отчет командированного за границу приват-доцента Московского университета Василия Истрина за вторую половину 1894 года (продолжение) // ЖМНП. Часть CCCVII, сентябрь. СПб., 1896. С. 8-9). Новое исследование и несомненную атрибуцию рукописи как перевода ОР произвел в начале XX в. А. И. Яцимирский, опубликовав результаты изучения памятника в «Описании южно-славянских и русских рукописей заграничных библиотек» (Том. І. Вена. Берлин. Дрезден. Лейпциг. Мюнхен. Прага. Любляна // Сборник отделения русского языка и словесности Императорской академии наук. Т. 98. СПб., 1921. С. $855-856)$. 1682.

${ }^{14}$ Joh.Am.Comenii Orbis sensualium pictus... Noribergae, sumt. Mich. et Joh. Friderici Endteri,

${ }^{15}$ Куприянова Т. Г. Первая династия российских издателей. М., 2001.

16 Зырянов B. B. Что читали и где учились // Россия в эпоху Петра Великого: путеводитель путешественника во времени. М., 2016. С. 279. 
В. Г. Безрогов. К вопросу о ранних переводах «Orbis sensualium pictus» Яна Амоса Коменского...

хранился до сих пор. При расплетании в центральный разворот каждой тетради вшивался одинарный чистый лист, а между остальными разворотами вкладывались двойные. Потом были по новой образованы тетрадки, сшиты, пересчитаны и сплетены в книгу уже с белыми страницами в каждом развороте между отпечатанными страницами - с картинками налево и текстом направо от чистого листа. Новые тетради сочтены. В нумерацию пустые страницы не включены, хотя подсчет тетрадей учитывает их тоже (подсчет славянскими буквенными вперемежку с арабскими числительными: арабским числом, например, подписана 9-я тетрадь на с. 80а; подсчет тетрадей проведен по всей книге). Есть ошибки раскладки расплетенных страничек внутри одной из тетрадок: лист со страницами 123-124 идет перед 121-122 и, соответственно, 119-120 перед 117-118. Рядом с римскими цифрами, обозначающими номер главы, в ряде мест вписаны арабские - где карандашом, где чернилами (35-XXXV, с.74; 36-XXXVI, с.76; 37-XXXVII, c.78; 38-XXXVIII, c.80; 39-XXXIX, c.82; 40-XL, c.84; 41-XLI, c.86; 42XLII, c.88; 43-XLIII, c.90; 44-XLIV, c.92; 45-XLV, c.94; 46-XLVI, c.96; 47-XLVII, c.98; 48-XLVIII, c.100; 49-XLIX, c.102; 50-L, c.104; 51-LI, c.106; 52-LII, c.108; 53LIII, c.110; 54-LIV, c.112; 55-LV, c.114; 56-LVI, c.116; 58-LVIII, c.120; 60-LX, c.124); в двух случаях арабские и римские числительные не соответствуют друг другу (59-LVII, c.118, но после 120 c. LVIII; 000-LIX, c.122, но после 124 с. LX; римская цифра LVII после LVIII насторожила того, кто вписывал арабские числительные, он решил с этим разобраться по-своему или просто пометил проблемное место для будущих размышлений). Славянскими числительными обозначен только порядковый номер большинства тетрадей.

Вшитая в печатное издание бумага от двух разных фабрик и немного отличается по качеству (белизне, тонкости, гладкости). Старшим научным сотрудником РГАДА Л. В. Мошковой было проведено изучение водных знаков - филиграней на пустых листах по всей книге. В одном случае это герб города Амстердама, в другом случае - лилия; состав и особенности начертания обоих знаков атрибутируют бумагу 1709 г. ${ }^{17}$ Таким образом, мы получаем явный terminus post quem для попытки рукописного перевода текста первых четырех тем учебника.

После учебного блока тематических текстов идут указатели и словари. По ним не дана сквозная нумерация страниц. Тетради справочного блока не расплетались, и белая бумага не добавлялась. Вероятно, словарную часть не планировали снабжать письменным переводом на русский, как это полагали сделать с учебной частью книги.

Помимо записи перевода первых четырех тем пособия встречается немецкая фраза на белом листе после страницы 46 для расшифровки темы 21 «Птицы полевые и лесные», Aves Campestres et Sylvestres. Она детализирует описание сторожевого журавля, der wachsame Kranich. Другая запись на чистом листе после страницы 224, тема 108 «Европа». Дана дополнительная заметка на немецком об этой части света. После страницы 226 вписана копия немецкого названия темы: Die Sittenlehre. Таким образом, мы видим, что книга с вплетенными чистыми

${ }^{17}$ Дианова Т. В. Филиграни XVII-XVIII вв. «Герб города Амстердама». Труды ГИМ. М., 1998. С. 97. № 308; Клепиков С. А. Филиграни и штемпели на бумаге русского и иностранного производств. XVII-XVIII века. М., 1959. С. 96. № 1427. 
страницами побывала в руках не только взявшегося ее переводить, а затем бросившего, но и человека, в трех местах посчитавшего необходимым внести ясность в немецкий пласт двуязычного печатного текста.

На последнем листе книги среди каракулей читается «год (an[no]) 1695 [или 1675]». А. А. Чума и писавшие после него авторы полагали 1695 г. возможной датой перевода, но теперь мы на основе изучения бумаги видим, что это не так. Дата вписана на страницу типографского блока до расплетания книги и снабжения ее белыми листами, на которых исполнен перевод. Однако в книге есть другое место, также содержащее хронологические пометы. B Index'e vocabulorum на листе Y 4 поверх всего текста на полях записан числовой ряд от 1 до 15, а потом идут годы вперемежку, вероятно, с месяцами: «1718 IIVI 17181920 30». Можно предположить, что книга в 1718 году была в руках некоего школяра (преподавателя, обоих?), и он вместе с простым написанием чисел размышлял о текущем и будущем временах, облекая эти свои размышления в цифру: февраль и июнь 1718-го (счет года шел тогда уже с января), 1719-й и последующие. 1718-й г. гораздо лучше подходит под вероятную дату «переводческой пробы», хотя переводчик и тот, кто вписал даты, конечно, не обязательно одно и то же лицо (даты записаны карандашом, перевод - чернилами).

Начало и первые четыре темы ОР (Введение, Бог, Мир, Небо, Огонь) снабжены черновым переводом на церковнославянский. Поскольку этот перевод до сих пор не опубликован, хотя о нем и упоминается во многих изданиях, мы взяли на себя труд расшифровать рукописный текст и опубликовать его здесь целиком. Он любопытен не только фактом своего существования, но и поиском эквивалентов (в данном случае, прежде всего, латыни), лексикой, формами слов, построением фраз.

Лл. 2а и 2а об. Invitatio. Einleitung. Призвание. У[читель]. Прииде, отрок, учитися мудрости. Отрок. Что аз есть мудрость? У. Все, что надобно, прямо разумети, прямо делати, прямо глаголати. О. Кто станет меня учити? У. Я з Богом. О. Како? У. Аз тебя поведу чрез вся, объявех тебе о вся, называв тебе вся. О. Се язд. Поведи меня именем Божиим. У. Прежде всех будет тебе учитися простые гласья, из которых состоит слово человеческое, которые зверь знает. Учим отворяти(?). Ишшо язык знать последованием. И твоя рука умеет писати. Потом пойдем в мир и узрим вся. Здесь имееши [или: вмести?] живое и глассное азбуки.

Лл. 6а и 6а об. I Deus. Gott. Бог есть от себя самого бывша прежде века. Caмосовершенное и блаженное существо. Естеством духовный и един. Ипостасию троиченей. Волею святый праведный милостивый ${ }^{18}$. Силою величаший, благостию блажайший, мудростию неизменный, свет неприступный, и токмо вся во всех. Везде и нигде. Всех вышшая благость. И един неизчерпаемый источник всей благости. Всех вещей, коих называем мир, како сотворитех, тако и властитех и сохранитель.

${ }^{18}$ В данном месте перевода 1710-х пропущено verax, «правдивый, истинный». Первая тема ни у Коменского, ни в переводе не имеет нумерации, отсылающей к изображению, в котором также нет чисел. Далее нумерация в оригинальном тексте, на картине и в переводе появляется. 
В. Г. Безрогов. К вопросу о ранних переводах «Orbis sensualium pictus» Яна Амоса Коменского...

Л. 8 II Mundus. Светъ. Die Welt. [«свет» вписан от руки тем же почерком, что и перевод]. Л. 8а об. Небо 12 имеет огнь, звезды. Облаки 2 висят в воздухе. Здесь птицы волант летают 3 [глагольная калька и перевод] под облоками. Рыбы 4 плавают в воде. Земля имеет горы 5 , лесы 6 , поля 7 , животная 8 , человеки 9. Тако исполнена суть обитателями своими четыре стихии, яже суть мира высочашая телеса или всех болша (рис. 1).
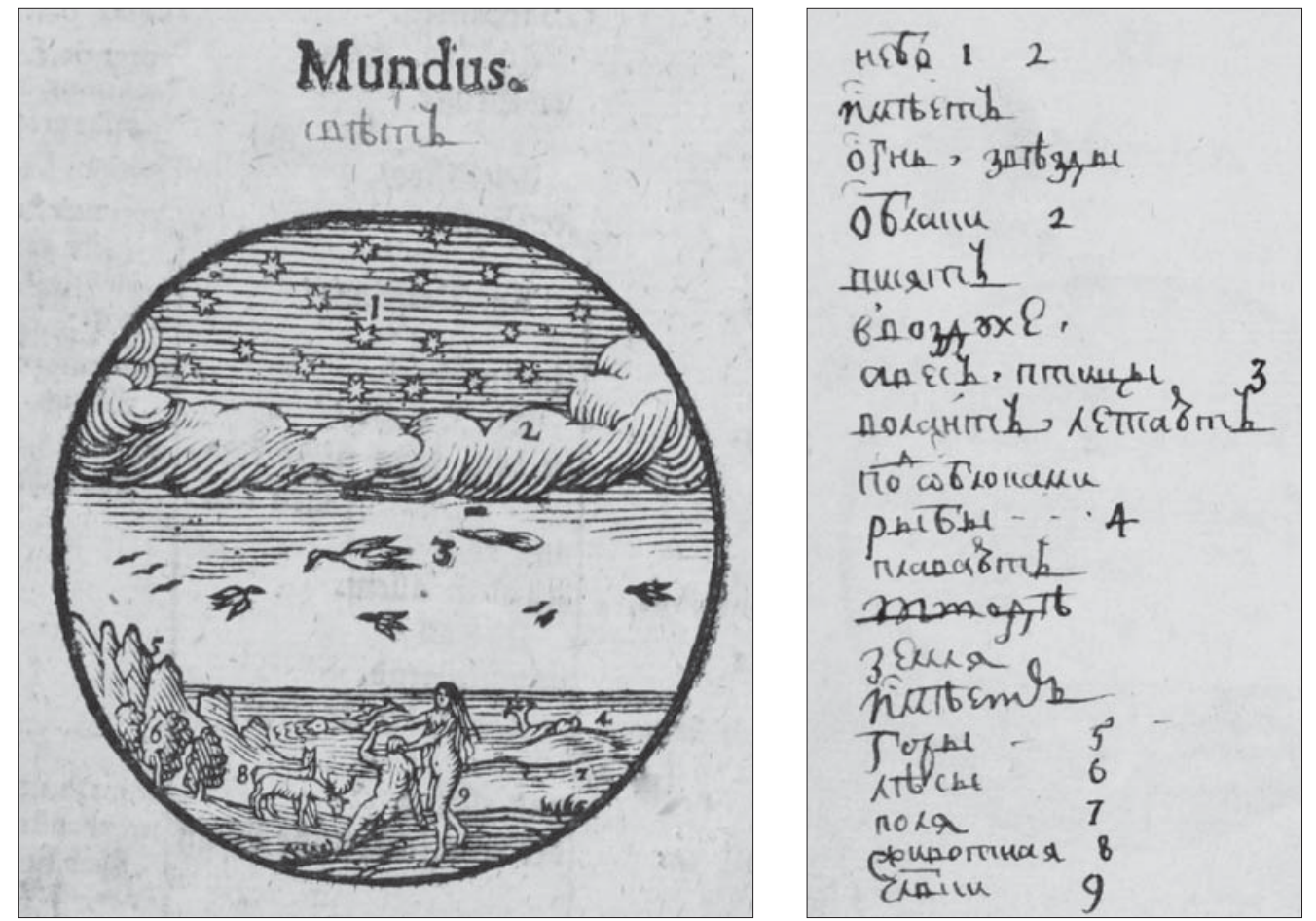

Puc. 1. Orbis sensualium pictus. Noribergae, 1682. РГАДА БМСТ № 2009. Л. 8 и 8 а об. Фотографии предоставлены Л. В. Мошковой

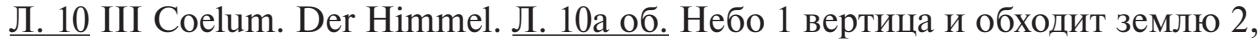
в середине стоящую. Солнце 3 , где ни есть, сияет непрестанно, хотя мрак или мрачное погодье 4 его от нас лишает, и творит своими лучами свет; свет день. В противлении суть тмы, отуды нощь. Сияет луна 7, и звезды 8 блистают или сияют. В вечере 9 есть зоря. Утро, или рано, денница, или зорница.

Л. 12 IV Ignis. Das Feuer. Л. 12 а. Огнь горит изпаляет. Его искра у кладом и кремня елиса; ( 1 нрзб.) 3 и от труда приемаетца сено спицею 4 и после свешу 5 или древо 6 сожжет [12а об.] и пламень 7 воздвигнет или пожар 8, который домы пожирает, или достигнет. Дымы 9 восходит оттуду и жжет. Прилепица к трубе или дымоволоку 10 черность или сажа. Из головни или древо горящее бывает погашенная или древо погашенное из углия огненнаго (горящия части главныя). Бывает черное углие напояе дом. Что останейса есть пепел и белы пепел (или горящий пепел) (рис. 2). 

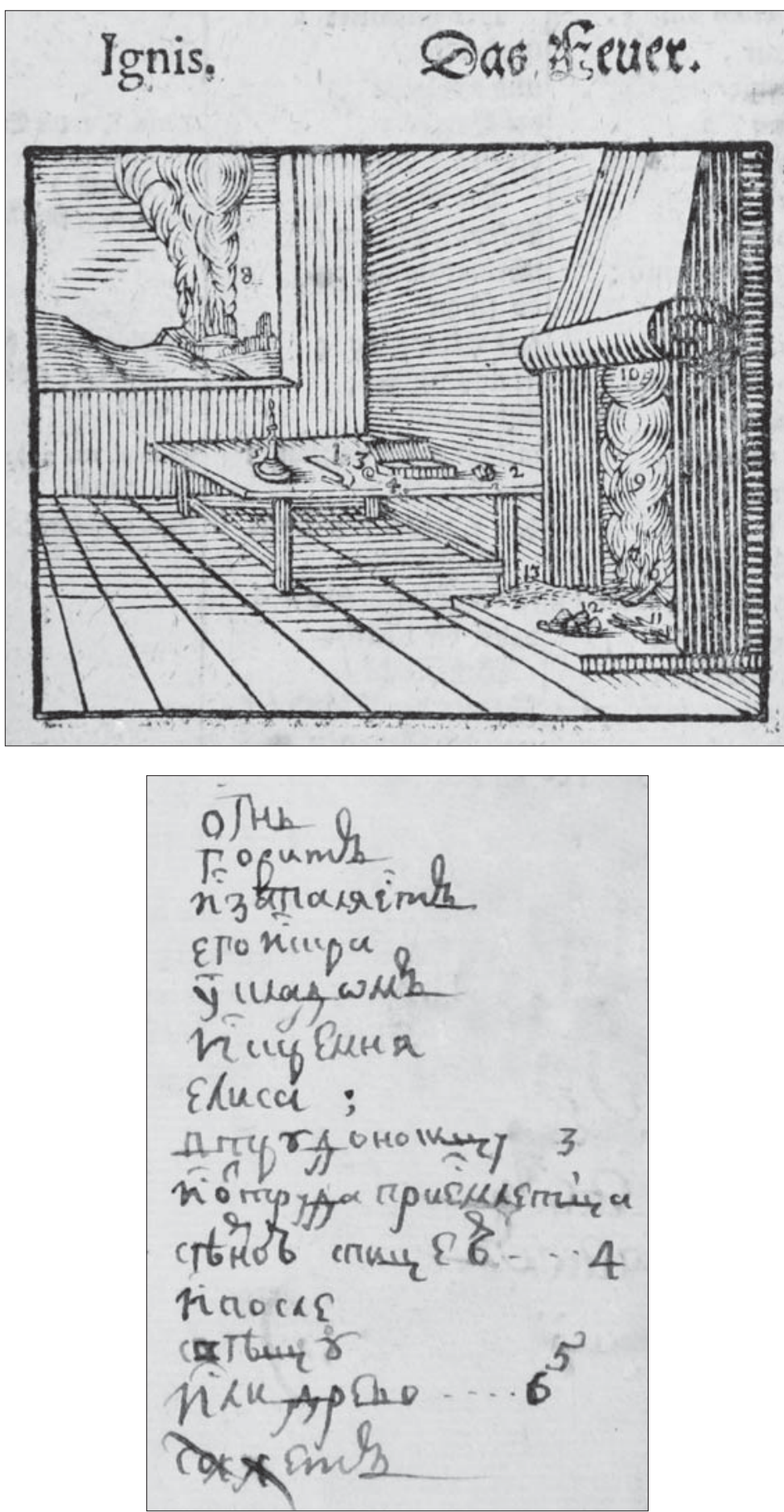

Puc. 2. Orbis sensualium pictus. Noribergae, 1682. РГАДА БМСТ № 2009. Л. 12 и 12 а об. Фотографии предоставлены Л. В. Мошковой 
В. Г. Безрогов. К вопросу о ранних переводах «Orbis sensualium pictus» Яна Амоса Коменского...

Перевод четвертой темы сделан по содержанию менее тщательно, он дальше отстоит от латинского оригинала, нежели переводы введения и первых трех тем. Латинский текст в издании 1682 г. почти не отличается от тех книг, из которых он был взят для латинско-русских воспроизведений «Мира чувственных вещей в картинках» 1941 и 1957 гг., за исключением в нескольких местах иного порядка слов, не влияющего на смыслы перевода, и применения в именах существительных прописных букв наподобие немецкого текста, что в нюрнбергской версии 1682 г. отсутствует. Поэтому мы отсылаем читателя к публикациям 1941-1957 гг. и не воспроизводим здесь латинский оригинал.

Трудно сказать, почему был приостановлен начатый в 1710-х гг. перевод ОР, для которого было подготовлено вновь переплетенное издание. Первые три главы переведены близко к тексту; четвертая не буквально, но тоже без спешки; введение, наоборот, передано точно, но уже явно наспех и для себя: строки идут наискосок и графика показывает небрежное отношение к записи, явно не рассчитанной на демонстрацию кому бы то ни было.

Таким образом, нюрнбергское издание ОР 1682 г. с вплетенными в него чистыми листами, переводом введения и четырех тем, сделанным в начале 1710-х гг., представляет собой первое по хронологии материальное свидетельство предпринятой попытки перевода ОР Коменского на русский язык. Можно предположить, что необходимость перевода ОР была в гораздо большей степени осознана не в момент открытия и прогресса московских «немецких школ», а в момент прекращения их деятельности и исчезновения соответствующих учителей на повседневном горизонте московской жизни вокруг 1715 г. Уменьшение возможностей учить языки с учителем могло стать стимулом попыток перевести пособие с тем, чтобы перевод заменил живых наставников.

\section{Пражский перевод второй половины 1710-х годов}

Работу с изданием 1682 г., сохранившуюся в РГАДА, оттеняет рукопись из фондов библиотеки Национального музея в Праге (MS IX.E.41). Полный перевод ОР уместился на 45 листах размером $165 \times 210$ мм $^{19}$. Бумага с филигранями Pro

19 Данные о манускрипте URL: http://www.manuscriptorium.com/apps/index.php?direct= record\&pid=RTRBAR-set20100113_73_169003\#search, а также в каталоге: Bartoš F. M. Catalogus codicum manu scriptorum musaei nationalis Pragensis. Pars secunda. Pragae, 1927. № 2533. URL: http://147.231.53.91/src/index.php?s=v\&cat=36\&bookid=380\&page=124. Бартош ссылается на А. И. Яцимирского, указавшего, что рукопись поступила из Лешно (Польша), будучи приобретена вместе с тремя другими рукописями: латинской грамматикой церковнославянского языка ок. 1727 г. (15 листов того же размера, кат. № 2532, шифр хранения IX.Е.40), отрывком «Wie ist es mit der Constructione Conjunctivi und Substantivi bewandt? (его атрибутика и местоположение на данный момент мне неизвестны, в каталоге Бартоша он не упоминается, только у Яцимирского; Бартош пишет о комплексе из трех рукописей) и русскоязычным фрагментом введения во французский язык, который датирован XVIII-XIX вв. (4 листа, размер 160х210, кат. № 2563, шифр хранения IX.F.34) Все три рукописи были объединены в папку «из грубой оберточной бумаги». На папке и ее корешке значится «Н. Conzet. Russische Grammatica. Varia Russica. Vestibulum Hymni. Colloquia etc. a D.L.B.de H... sa Submissa. Нassea» (Яцимирский А. И. Описание южно-славянских и русских рукописей заграничных библиотек. Том. I. Вена. Берлин. Дрезден. Лейпциг. Мюнхен. Прага. Любляна // Сборник отделения русского языка и сло- 
Patria и Maid of Dort производилась как минимум с 1683 по 1799 г. Почерк, согласно экспертизе ст. науч. сотр. РГАДА Л. В. Мошковой и вед. науч. сотр. Ин-та славяноведения РАН А. А. Турилова, характерен для $1710-\mathrm{x}-$ начала $1720-$-х гг. ${ }^{20}$ По их наблюдению, использование переводчиком славянских числительных с параллельным/последующим указанием их арабских эквивалентов свидетельствует о том, что переводчик обучался в традиционной системе, а новую графику осваивал потом сам. Эти данные согласуются с биографиями переводчиков Феофила Кролика и Ивана Воейкова, а также их помощника Максима Суворова (Кролик на момент отправки в Прагу был префектом «московских славенолатинских школ», а Суворов там учился). Опыт перевода типологически расходится с переводами на вплетенных в издания ОР листах.

Приведем в качестве примера перевод главы 1-й (рис. 3) в расшифровке А. И. Яцимирского (л.2 об.): «Глава 1-я Бог есть сам из себе от века во век совершенные и блаженнеишее вещество естеством духовный и един во ипостасех троичныя волею святыий праведныи благодатию правдивы мощчию величайший благодатию бладеннеиший премудростию неизверныий свет непритупны дя токмо вся во вся везде и нигде высочаишая благость и един неисчерпаемыйи колодез всея благодати всех вещей что мы нарицаем мир яко сотворитель тако и обла<го>датель и одержатель».

Полный рукописный перевод ОР не свидетельствует о выполнении его в процессе школьного или домашнего обучения по нему, как издания 1682 и 1732 г. (о втором мы скажем ниже), хотя переводился с книги, а не с рукописи, как полагал исследовавший данный перевод А. И. Яцимирский ${ }^{21}$. Скорее «пражский вариант» стал результатом внимания потенциального педагога к возможному

весности Императорской академии наук: Т. 1-101. Т. 98. СПб., 1921. С. 855-856). Расстояние между Лешно и Прагой в зависимости от выбора дороги 250-340 км. Рукопись перевода ОР явно центральная по объему и значимости для ее владельцев среди приобретенного музеем комплекса из четырех/трех манускриптов. Мигрировала ли она в Лешно к месту памяти о пребывании там в 1625/28-1641 гг. самого Коменского, а потом вернулась в Прагу (приобретена в Лешно вместе с письмами Коменского), или история была иной, мы сейчас не можем сказать.

20 Эта экспертиза уточняет мнения М. А. Коркунова, который полагал, что почерк «принадлежит к первым годам XVIII или даже к последним XVII века» (О книге Иоанна Амоса Коменского: Видимый свет // Известия II Отд. Акад. Наук. IV. 1855. Стлб. 201), и А. И. Яцимирского, относившего манускрипт ко второй четверти XVIII в. (Яцимирский. Указ. соч. C. 850).

${ }^{21}$ А. И. Яцимирский в тщательном и подробном аналитическом описании рукописи тезис о том, что она выполнялась тоже с рукописи (немецкой?), основывает на двух критериях: a) несовпадения названия с печатными вариантами, которые могли быть доступны (но этот критерий не работает, поскольку многие переводы того времени передавали титул часто либо сокращенно, как в нашем случае, либо в пересказе); б) на л.32об. сделана заметка по поводу главы 108: «сия места позже потому что в подлинной книге не написано ничего» (нам известны многие издания ОР с утраченными в процессе их применения страницами, тут мог быть такой же случай: дефектный экземпляр печатной книги и необходимость восстановить текст по другой копии; слово «написано» могло применяться и к напечатанному тексту; слово «книга» относилось и к печатным версиям; относительная точность перевода, сопоставляемая сейчас с печатными экземплярами ОР того времени, и отсутствие рукописи-прототипа также свидетельствуют в пользу перевода с книги). См.: Яцимирский А. И. Указ. соч. С. 850-856. 


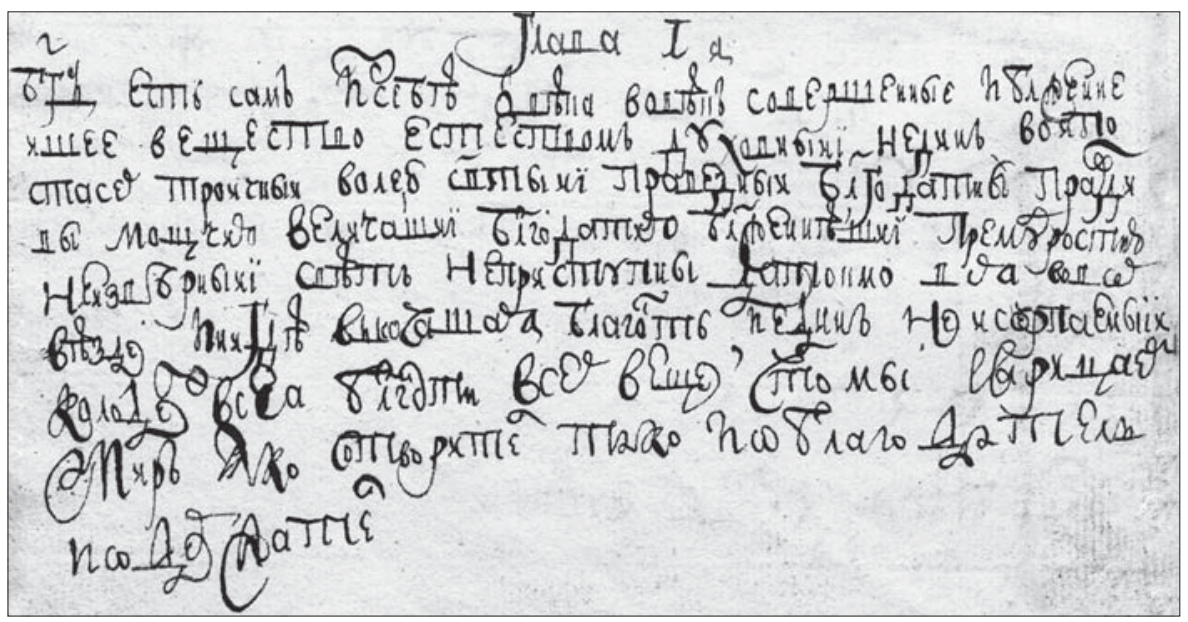

Puc. 3. Рукописный перевод Orbis sensualium pictus. 1710-1720-е г2.

Национальный музей в Праге. MS IX.Е.41. Л. 2 об. Фотография предоставлена Я. Хобжой

инструментарию либо для обучения нерусских учеников русскому (аналогично английскому проекту Консетта), либо для обучения русских учеников немецкому, латыни и, возможно, другим двум языкам по приобретенному М. Суворовым изданию 1679 г. Если принять вторую версию, то мы видим исток той идеи, которая приведет в первому пятиязычному изданию 1768 г. Однако нам представляется более вероятной первая версия. В ее пользу свидетельствует как перевод отдельно от издания, так и факт оставления рукописи в западнославянских странах. Известно, что М. Суворов привез с собой в Россию не только библиотеку из ста разных европейских книг (включая ОР 1679 г.), но и несколько рукописей. Перечень рукописей не сохранился, но среди них явно не было перевода ОР, оставленного вне русскоязычных территорий. После возвращения из Праги Суворов выезжал на короткий срок в Вену, а с 1726 по 1732, а возможно, и по 1737 г. был учителем русского и, вероятно, других предметов в «славянских школах» нескольких сербских городов австро-венгерской монархии. По-видимому, его миссионерские интересы начали формироваться еще в годы первого контакта с западнославянскими народами. Их возникновение могло отразиться и в факте его работы над переводом ОР. Примененный для перевода облегченный вариант церковнославянского мог восприниматься Суворовым (и/или его старшими коллегами) основой для чаемого и предполагавшегося будущего православного миссионерства в центрально- и южноевропейских направлениях. В таком случае работа над полным вариантом ОР приобретала особый смысл. Идеологическая поддержка помогла выполнить полный перевод пособия. Ученического интереса, как мы увидели в книге 1682 г. издания, на такой большой и длительный труд не хватало. «Пражский» перевод требует особого исследования как пример попытки создания «учебника нового типа» в контактной зоне, где среди славянского населения распространялись самые разные конфессии и деноминации и где их постоянный диалог порождал уже с XVI в. потребность и в православных 
кириллических ответах на иную графику в уже многочисленных вариантах начальных учебных пособий, разработанных для славян католиками, лютеранами, кальвинистами, арианами, протестантами-евангелистами и др. ${ }^{22}$ Можно предположить, что педагогическое наследие епископа «объединенных братьев», как называли себя члены моравских общин, рассматривалось и для его использования с другой стороны межконфессиональных отношений. Однако основная линия интереса к ОР на русском языке была связана все же со светскими учебными заведениями.

\section{Издание 1732 года}

В собрании Музея книги Российской государственной библиотеки имеется OP с аналогичным образом вплетенными чистыми листами и попыткой перевода - только теперь уже на французский и русский ${ }^{23}$. Титул и часть предисловия утрачены, место и дата издания установлены сотрудником РГБ и проверены мной по электронной копии того же издания из другой библиотеки. После предисловия на титульной странице самого текста над титулом имеется запись «Из книг Василия Дешисова (Демикова, Дешикова, Динисова?)». Начиная со страницы 16 и по конец основного текста (с. 315), до Index titulorum вплетены пустые листы между страницами текста аналогично изданию 1682 г. в РГАДА. В индексах в начале и в конце вплетено по чистой странице. Нумерации тетрадей вручную, как в экземпляре РГАДА, нет. Бумага вплетена не в типографииизготовителе, она плотнее, чем та, на которой издан ОР в Нюрнберге в 1732 г. По филиграням определяются 1734-1736 гг, российское производство ${ }^{24}$. Из этого следует, что расплетали книгу и вшивали чистые листы уже в России. Возможно, это следы еще одного переводческого проекта, теперь уже сразу на французский (новые веяния 1730-х!) и русский языки одновременно 25 . Вновь сшитые тетради никак не нумерованы - ни арабскими, ни славянскими буквенными числитель-

${ }^{22}$ Averjanova L. \& V. Bezrogov. Primer as the Shield of Faith: Religious Culture and Education on the Eve of the $18^{\text {th }}$ Century in Russia // The History of Korean Education. 2015. Vol. 37. no. 3. P. $123-140$.

${ }^{23}$ Joh. Amos Comenii Orbis Sensualium Picti Pars Prima. Hoc est : Omnium fundamentalium in mundo rerum, \& in vita actionum, Pictura \& Nomenclatura. Editio auctior \& emendatior, cum Titulorum juxta atque Vocabulorum Indice. = Die sichtbaren Welt Erster Theil. Das ist: Aller vornehmsten Welt-Dinge, und Lebens-Verrichtungen, Vorbildung und Benahnung. Aufs neue aufgelegt, an vielen Orten, neben einem Titel- und Wörter-Register verbessert; auch mit gantz neuen, schönern und deutlichern Figuren, versehen. Editio auctior \& emendatior, cum Titulorum juxta atque Vocabulorum Indice. Noribergae, 1732. [16], 315, [109] p.

${ }^{24}$ Филиграни РФ в картуше и АГ контрамаркой или в картуше - по С. А. Клепикову, 1734-1736 годы. URL: http://www.opentextnn.ru/history/arkheography/specification/?id=3023, Таблица филиграней и водяных знаков на бумаге русского производства XVIII — начала XX в., № 655 и 13$)$.

${ }^{25}$ Об интересе русского общества 1730-х гг. к пособиям по французскому языку см. материалы проектов «Формирование академической лингвистической традиции: «Грамматика французская и русская» (1730) - лингвистический, историко-культурный и источниковедческий аспекты» и «Формирование русской академической грамматической традиции: «Новая французская грамматика» В. Е. Теплова (лингвистический, историко-культурный, терминологический, лексикографический аспекты)» на сайте: URL: http://lomonosov.iling.spb.ru. 
В. Г. Безрогов. К вопросу о ранних переводах «Orbis sensualium pictus» Яна Амоса Коменского...

ными - как в экземпляре 1682 г. издания из РГАДА. Между 24 и 25, 32 и 33, 40 и 41, 54 и 55, 56 и 57, 58 и 59, 72 и 73 страницами белый лист отсутствует. Между страницами 156 и 157 плотный лист белой бумаги с правой стороны, между 250 и 251 с левой имеет следы вдавленности от написанного текста на листе, лежавшем ранее сверху него до включения в переплет. В первом случае впечатление, что сверху писали упражнения в прописях. Следы на листе между 222 и 223 страницами явно не от прописей. Книга отреставрирована, предположительно, в XIX-XX вв. Старый переплет не сохранен.

Впечатление, что переводчик имел дело уже с дефектным экземпляром (потому и владельческая надпись не на стандартном месте, а на реальном титуле основного учебного блока, который при утрате основного титула и большей части предисловия стал вратами в книгу). Поэтому, вероятно, он выбрал для пробного перевода не первые темы, а отступил от поврежденного начала книги.

Перевод темы VI «Вода». Лист 16а об. между страницами 16 и 17. Чистый лист поделен вертикальной чертой пополам. Французский текст аккуратным ученическим почерком со следами русской и немецкой графики вписан в левом столбце. Правый остался чистым.

L'Eau Sort de la Fontaine .1. [не точки, но кавычки по нижней линии строки] de coule dans le Torant .2. coule au Ruisseau .3. Noupit dans l'etang .4. coure au fleuve .5. elle se tourney en moulinet .6. fait de marais .7. Le fleuve à de Rivages .8. le Mer fait des bords .9. des Golfes .10. des en coleurs .11. des isles .12. decletrois de terre .14. de detrois de mer .15. et à des Ecueils .16.

Перевод темы VII «Облака». Лист 18а и 18а об. между страницами 18 и 19. Чистый лист поделен вертикальной чертой пополам. Французский текст вписан в левом столбце. Правый остался чистым. Перевод дан вровень с печатным текстом, начинающимся слева под картинкой.

La Nüe. [далее с отступом-интервалом на той же строке справа, над вторым столбцом славянское число «7»; можно считать его свидетельством, что в правом столбце предполагался перевод на церковнославянский]. Не выделены прописные буквы и не отмечены окончания фраз - мы расставили знаки препинания в соответствии с латинским оригиналом в издании 1732 г.

De l'eau s'eslere la vapeur 1. D'ou se forme la nüe, 2 et après de la terre un brouillard 3. [следующая фраза переведена с латинской, переданной иначе, чем в переизданиях 1941-1957 гг., опиравшихся на варианты 1658-1667 гг., в оригинале 1732 она дана так: E nube stillat (defluit guttátim) pluvia 4 f.1 \& imber. m.3.] De la nüe de goute la pluÿe 4 et la Grosse [переводчик «огерманивает» французскую фразу сам, в немецком тексте стоит Plazregen] pluÿe. La quelle etant gelée en grele 5, [л. 18а об.] a'demi gellée la neige 6, cehau ffee brullure se cheresse. En une nüe [почерк не француза по рождению, ученически-старательный, «ц» оторвал от «пе», человек с родным французским так бы не поступил], plurieuse, qui est oposée au Soleil se montre L'Arcen ciel 7. Une goute Tombant dans l'eau fait des Boullions Bruteille 8 quantite de [на этом перевод обрывается, тема 7 переведена не полностью].

Переводом двух тем дело и завершилось. Вторая попытка типологически очень похожа на первую: расплетается оригинальное издание, в основную часть с темами, картинками и текстами добавляются чистые листы. Затем делается но- 
вый переплет. В итоге создается книга для постоянных упражнений не только в чтении, выучивании слов и т. д., но и в письменном переводе на родной или другой новоевропейский язык, а не на латынь. К переводам с латыни и на латынь ученик приступал уже после проработки ОР.

Делался ли «учебник с чистыми листами» только для частных упражнений в рамках преподаваемого курса? Или с надеждой потом продать типографу для переиздания с включением русского и французского вариантов текста к тем же картинкам? Изготовлялись ли подобные «учебники-записные книжки переводчика» для домашнего, досугового или последующего профессиональносправочного употребления? Для чего-то иного? Прекращалась работа из-за сложности, охлаждения, отказа от заказа, чего-то еще? Мы пока не знаем. Но явно видим интерес к переводу ОР на русский и французский, порождающий некую практику. В отсутствие доступного печатного латино-немецко-французского издания, чтобы вписать туда только русский вариант, обучающийся создает основу для материализации четырехъязычного пособия в процессе учения. В переводе от 1710-х гг. работа ученическая, самодидактическая или на предполагаемый заказ. В 1730-е гг. она явно ученическая. В любом случае такая схема работы вела к многоязычным переводам ОР, воплотившимся впервые в латино-руссконемецко-итальяно-французском московском издании 1768 г. «Доисторический» интерес к русскому ОР имел два пика: вторую половину 1710-х (светский и, предположительно, миссионерский) и середину - вторую половину 1730-х гг. (по преимуществу светский). В первом случае трехъязычие (но уже не по модели Букваря и Лексикона Федора Поликарпова) полагалось достаточным, во втором добавился интерес к французскому: наступила новая эпоха.

Возможно, изучение других книжных коллекций уточнит и добавит детали в эту периодизацию пробуждения интереса российской педагогии к ОР и его переводам как упражнениям в школах или дома. Первые ростки постепенно привели к успешной работе над российским изданием всего учебника, в основу которой было положено, скорее всего, четырехъязычное немецко-латино-итальянофранцузское издание, выпущенное в Нюрнберге Й. Эндтером в 1755 г. ${ }^{26} \mathrm{~K}$ нему был присовокуплен русский вариант текста, но удалены все иллюстрации (поскольку, как было сказано в предисловии, иллюстрации в книге не качественны по сравнению с отдельными настенными изображениями, а также «натуральными вещами, раскрашенными фигурами, моделями и проч.», кои каждое «изрядно распоряженное училище» иметь обязано) ${ }^{27}$. Московское издание 1768 г. завершило предысторию и начало историю переводов ОР в России.

${ }^{26}$ А. И. Яцимирский пишет, что прототипом стало издание 1707 г., но французские и итальянские переводы, имеющиеся в нем, отличаются от воспроизведенных в 1768 г. в Москве, а варианты издания 1755 г. полностью совпадают. См.: Яцимирский А. И. Указ. соч. С. 854, а также: URL: http://digital.staatsbibliothek-berlin.de/. Московские пятиязычные издания явно готовились на основе имевшихся в середине XVIII в. четырехъязычных с вопроизведенным в них набором языков.

${ }^{27}$ Иоанна Амоса Комения Видимый свет на латинском, российском, немецком, италианском и французском языках представлен, или Краткое введение, которым изъясняется, что обучающемуся юношеству лехким способом не только языку, разумным упражнением, но также и вещи достойныя знания самонужнейшия должны быть вперены, : Изо ста пятидесяти одной 
В. Г. Безрогов. К вопросу о ранних переводах «Orbis sensualium pictus» Яна Амоса Коменского...

Ключевые слова: начальное образование, Ян Амос Коменский, школа, перевод, би- и полилингвальное обучение.

\section{Список литературы}

Безрогов В. Г., Куровская Ю. Г. К истории названий учебных книг как способов организации образовательной информации: Orbis pictus Коменского // Символическая вселенная ребенка: между информацией и знанием: Сб. науч. тр. / К. В. Султанов, ред. СПб., 2016. C. 217-225.

Безрогов В. Г., Куровская Ю. Г. Международный аспект образовательного пространства: Orbis pictus Коменского как проект учебника для всех стран // Информационное пространство и дети: образовательные возможности и манипулятивные воздействия: Сб. науч. тр. / К. В. Султанов, ред. СПб., 2016. С. 298-307.

Грасгофф Х. Из истории связей Берлинского общества наук с Россией в 20-х годах XVIII в. // XVIII век. Сб. 7: Роль и значение литературы XVIII века в истории русской культуры. Л., 1966. С. 59-65.

Дианова T. В. Филиграни XVII-XVIII вв. «Герб города Амстердама». Труды ГИМ. М., 1998.

Зырянов В. В. Что читали и где учились // Россия в эпоху Петра Великого: Путеводитель путешественника во времени. М., 2016. С. 247-287.

Иоанна Амоса Комения. Видимый свет на латинском, российском, немецком, италианском и французском языках представлен, или Краткое введение, которым изъясняется, что обучающемуся юношеству лехким способом не только языку, разумным упражнением, но также и вещи достойныя знания самонужнейшия должны быть вперены, : Изо ста пятидесяти одной главы состоящее, из которых каждая вместо надписи и содержания из Священнаго Писания взятым свидетельством означена, и с реестром самых нужнейших российских слов, которой вместо лексикона для употребления российскаго юношества служить имеет, место на пяти языках дополнить может, изданное. [M.], 1768.

Каразин В. Н. Каталог славяно-российским рукописям (погибшим в 1812 году) профессора Баузе // Чтения Общества истории и древностей российских при Московском университете. М., 1862. Кн. 2. Отд. 5.

Карева Н. В. Становление традиции грамматического описания русского языка (17301750-е гг.) // Литературная культура России XVIII века. Вып. 4. СПб., 2011. С. 90-109.

Клепиков $C$. A. Филиграни и штемпели на бумаге русского и иностранного производств. XVII-XVIII века. М., 1959.

Командорова Н. И. Русская Прага. М., 2009.

Куприянова Т. Г. Первая династия российских издателей. М., 2001.

Моисеева Г. Н. «Собрание российских древностей» профессора Баузе // Труды Отдела древнерусской литературы. Т. 35. Л., 1980. С. 301-344.

Мыльников А. С. Русские переводчики в Праге. 1716-1721 гг. // XVIII век. Сборник 9. Л. 1974. C. 279-296.

Отчет командированного за границу приват-доцента Московского университета Василия Истрина за вторую половину 1894 года (продолжение) // ЖМНП. Часть СCCVII, сентябрь. СПб., 1896. С. 1-25.

главы состоящее, из которых каждая вместо надписи и содержания из Священнаго Писания взятым свидетельством означена, и с реестром самых нужнейших российских слов, которой вместо лексикона для употребления российскаго юношества служить имеет, место на пяти языках дополнить может, изданное. [М.], 1768. С. 10. Реально наблюдающий ныне нюрнбергское издание 1755 г., равно как и более ранние, такого суждения о некачественности не выскажет. Однако глаза московских типографов XVIII в. вынесли иной вердикт иллюстрациям ОР. 
Пекарский П. П. Наука и литература въ Россіи при Петре Великомъ: изследованіе П. Пекарскаго. СПб., 1862. Т. 1.

Рыжков А. Н. Образование в «немецких» школах Москвы в первой четверти XVIII века // Вопросы образования. 2007. № 2. С. 368-382.

Скорвид С. С. Слово Я. А. Коменского в России: из истории перевода // Наследие Яна Амоса Коменского в контексте проблем современного образования. СПб., 2007. C. $113-122$.

Топоров В. Н. Эрнст Глюк, немецкий подвижник латышского и русского просвещения // Балто-славянские исследования. 1984. М., 1986. С. 243-262.

Фундаминский М. И. К истории библиотеки Т. Консетта // XVIII век. Сборник 21: Памяти Павла Наумовича Беркова / Н. Д. Кочетков, отв. ред. СПб., 1999. С. 40-52.

Чума A. A. Ян Амос Коменский и русская школа (до 70-х годов XVIII века). Братислава, 1970.

Яцимирский А. И. Описание южно-славянских и русских рукописей заграничных библиотек. Том. І. Вена. Берлин. Дрезден. Лейпциг. Мюнхен. Прага. Любляна // Сборник отделения русского языка и словесности Императорской академии наук: Т. 1-101. Т. 98. СПб., 1921. С. 850-856.

Averjanova L. \& V. Bezrogov. Primer as the Shield of Faith: Religious Culture and Education on the Eve of the $18^{\text {th }}$ Century in Russia // The History of Korean Education. 2015. Vol. 37. no. 3. P. $123-140$.

Bartoš F. M. Catalogus codicum manu scriptorum musaei nationalis Pragensis. Pars secunda. Pragae, 1927. № 2533. URL: http://147.231.53.91/src/index.php?s=v\&cat=36\&bookid=380 \&page $=124$.

Gluck J. E. Grammatik der russischen Sprache. 1704 / Hrsg. und mit einer Einleitung versehen von H. Keipert, B. Uspenskij und V. Zivov. Koln; Weimar; Wien, 1994.

Joh. Am. Comenii Orbis Sensualium Picti Pars Prima. Hoc est : Omnium fundamentalium in mundo rerum, \& in vita actionum, Pictura \& Nomenclatura. Editio auctior \& emendatior, cum Titulorum juxta atque Vocabulorum Indice. $=$ Die sichtbaren Welt Erster Theil. Das ist: Aller vornehmsten Welt-Dinge, und Lebens-Verrichtungen, Vorbildung und Benahnung. Aufs neue aufgelegt, an vielen Orten, neben einem Titel- und Wörter-Register verbessert; auch mit gantz neuen, schönern und deutlichern Figuren, versehen. Editio auctior \& emendatior, cum Titulorum juxta atque Vocabulorum Indice. Noribergae, 1732. [16], 315, [109] p.

Joh.Am.Comenii Orbis sensualium pictus... Noribergae, sumt.Mich.et Joh.Friderici Endteri, 1682.

Johann Ernst Gluck 1653-1705: Pastor, Philologe, Volksaufklarer im Baltikum und in Russland (Fremdsprachen in Geschichte und Gegenwart) / Hrsg. H. Glück, I. Polanska. Wiesbaden, 2005.

Mach Dich auf und Werde Licht - Celies Nu, Topi Gaiss - Zu Leben und Werk von Ernst Gluck (1654-1705): Akten der Tagung Anlasslich Seines 300.Todestages vom 10. bis 13. Mai 2005 in Halle (Saale) / Hrsg. C. Shiller, M. Grudule. Wiesbaden, 2009.

Philipp Balthasar Sinold von Schütz (Hrsg.). Die europäische Fama, welche den gegenwärtigen Zustand der vornehmsten Höfe entdecket. Der 35. Theil. Leipzig, 1714 (repr.1705, 1708).

Pilz K. Die Ausgaben des Orbis Sensualium Pictus. Eine Bibliographie. Nürnberg, 1967. 
В. Г. Безрогов. К вопросу о ранних переводах «Orbis sensualium pictus» Яна Амоса Коменского...

St. Tikhon's University Review. Series IV: $\rho_{\text {edagogy. }}$ sychology. 2017. Vol. 45. P. $11-30$
Bezrogov Vitaly

Doctor of Science in Education Institute of Developmental Strategy of Education, Russian Academy of Education 5/16 Makarenko ul., Moscow 105062, Russian Federation

\title{
EARLy UnPUblished Russian TransLations of Orbis SENSUALIUS PICTUS BY Jan Amos Comenius
}

\begin{abstract}
V. BezRogov
The paper examines the emergence of interest (in Russian pedagogical culture) in the textbook A World of Things Obvious to the Senses Drawn in Pictures written by the great Moravian educator Jan Amos Comenius. Through the study of the West European editions with handwritten marginalia and unpublished manuscripts containing translations of this textbook from German and Latin into Russian, stages of the prehistory of the first complete edition of Orbis sensualium pictus in Russian are reconstructed. The first survived Russian translations date from the 1710s, when "German schools" ceased to work in Moscow and there appeared an "educational vacuum" in the teaching of foreign languages. The second stage is the period of the 1730s, when the necessity of a multilingual manual emerged. There were attempts at transforming the Latin-German textbook into German-Latin-French-Russian. Approximately semicentennial period of increasing interest in the Orbis pictus results in the Latin-Russian-German-ItalianFrench edition of 1768, which is based on the four-language Nürnberg edition of 1755 . The study of contacts between several pedagogical cultures related to the preparation of textbooks appears to be a significant part of the research into the history of primary education in the Orthodox region.
\end{abstract}

Keywords: elementary education, Jan Amos Komenský (Jan Amos Comenius), school, translation, bilingual and multilingual education

\section{References}

Averjanova L. \& V. Bezrogov. Primer as the Shield of Faith: Religious Culture and Education on the Eve of the $18^{\text {th }}$ Century in Russia, in: The History of Korean Education. 2015. Vol. 37. no. 3. P. 123-140.

Bartoš F. M. Catalogus codicum manu scriptorum musaei nationalis Pragensis. Pars secunda. Pragae, 1927. № 2533, URL: http:// 147.231.53.91/src/index.php?s $=$ v\&cat $=36$ $\&$ bookid $=380 \&$ page $=124$.
Bezrogov V. G., Kurovskaia Iu. G., K istorii nazvanii uchebnykh knig kak sposobov organizatsii obrazovatel'noi informatsii: Orbis pictus Komenskogo, in: Simvolicheskaia vselennaia rebenka: mezhdu informatsiei $i$ znaniem. Sb. nauchn. tr. ,ed. K. V. Sultanov, St. Petersburg, 2016, 217-225.

Bezrogov V. G., Kurovskaia Iu., G. Mezhdunarodnyi aspekt obrazovatel'nogo prostranstva: Orbis pictus Komenskogo kak 
Исследования: педагогика

proekt uchebnika dlia vsekh stran, in: Informatsionnoe prostranstvo i deti: obrazovatel'nye vozmozhnosti $i$ manipuliativnye vozdeistviia. Sb. nauchn. tr., ed. ,K. V. Sultanov, St. Petersburg, 2016, 298-307.

Chuma A. A., Ian Amos Komenskii i russkaia shkola (do 70-kh godov XVIII veka). Bratislava, 1970.

Dianova T. V., Filigrani XVII-XVIII vv. «Gerb goroda Amsterdama». Trudy GIM, Moscow, 1998.

Fundaminskii M. I., K istorii biblioteki T. Konsetta, in: XVIII vek. Sbornik 21: Pamiati Pavla Naumovicha Berkova, ed. N. D. Kochetkov, St. Petersburg., 1999. Iatsimirskii A. I., Opisanie iuzhno-slavianskikh i russkikh rukopisei zagranichnykh bibliotek. Tom. I. Vena. Berlin. Drezden. Leiptsig. Miunkhen. Praga. Liubliana, in: Sbornik otdeleniia russkogo iazyka i slovesnosti Imperatorskoi akademii nauk: T. 1-101. T. 98. St. Petersburg, 1921, 850-856.

Gluck J. E. Grammatik der russischen Sprache. 1704 / Hrsg. und mit einer Einleitung versehen von H. Keipert, B. Uspenskij und V. Zivov. Koln; Weimar; Wien, 1994.

Grasgoff Kh., Iz istorii sviazei Berlinskogo obshchestva nauk s Rossiei v 20-kh godakh XVIII v., in: XVIII vek. Sbornik 7: Rol' $i$ znachenie literatury XVIII veka $v$ istorii russkoi kul'tury. Leningrag, 1966, 59-65.

Johann Ernst Gluck 1653-1705: Pastor, Philologe, Volksaufklarer im Baltikum und in Russland (Fremdsprachen in Geschichte und Gegenwart) / Hrsg. H. Glück, I. Polanska. Wiesbaden, 2005

Kareva N. V., Stanovlenie traditsii grammaticheskogo opisaniia russkogo iazyka (17301750-e gg.), in: Literaturnaia kul'tura Rossii XVIII veka, St. Petersburg, 2011, 4.
Klepikov S. A., Filigrani i shtempeli na bumage russkogo $i$ inostrannogo proizvodstv. XVIIXVIII veka, Moscow, 1959.

Komandorova N. I., Russkaia Praga, Moscow, 2009.

Kupriianova T. G., Pervaia dinastiia rossiiskikh izdatelei, Moscow, 2001.

Mach Dich auf und Werde Licht - Celies Nu, Topi Gaiss - Zu Leben und Werk von Ernst Gluck (1654-1705): Akten der Tagung Anlasslich Seines 300.Todestages vom 10. bis 13. Mai 2005 in Halle (Saale) / Hrsg. C. Shiller, M. Grudule. Wiesbaden, 2009.

Moiseeva G. N., «Sobranie rossiiskikh drevnostei» professora Bauze, in: Trudy Otdela drevnerusskoi literatury, Leningrad, 1980.

Myl'nikov A. S., Russkie perevodchiki v Prage. 1716-1721 gg., in: XVIII vek. Sbornik 9. Leningrad, 1974, 279-296.

Pilz K. Die Ausgaben des Orbis Sensualium Pictus. Eine Bibliographie. Nürnberg, 1967.

Ryzhov A. N., Obrazovaniev «nemetskikh» shkolakh Moskvy v pervoi chetverti XVIII veka, in: Voprosy obrazovaniia, 2007, 2.

Skorvid S. S., Slovo Ia. A. Komenskogo v Rossii: iz istorii perevoda, in: Nasledie Iana Amosa Komenskogo $v$ kontekste problem sovremennogo obrazovaniia, St. Petersburg, 2007, 113-122.

Toporov V. N., Ernst Gliuk, nemetskii podvizhnik latyshskogo i russkogo prosveshcheniia, in: Balto-slavianskie issledovaniia, 1984, Moscow, 1986.

Zyrianov V. V., Chto chitali i gde uchilis', in: Rossiia v epokhu Petra Velikogo: putevoditel puteshestvennika vo vremeni, Moscow, 2016. 